\title{
Adipokinetic effect of corpora cardiaca extract in Valanga nigricornis (Burm.)
}

\begin{abstract}
1. The effect of injection of corpora cardiaca (CC) extract on haemolymph lipid concentration of V. nigricornis was studied.

2. The CC extract caused a marked increase in the haemolymph lipid, which attained a peak at about $11 / 2 \mathrm{hr}$ after injection. At longer intervals of up to $4 \mathrm{hr}$, this response was markedly diminished.

3. The results were considered in relation to the natural habit of the insect; it is suggested that the adipokinetic effect probably represents an adaptive mechanism to non-flight physiological conditions like starvation.
\end{abstract}

Keyword: Corpora cardiaca (CC) extract; Adipokinetic effect; Valanga nigricornis 